\title{
New technological concept of utilization animal and poultry waste
}

\author{
Natalia Mamas ${ }^{1, *}$, Artem Verbitsky $^{1}$, and Vladislav Verbitsky ${ }^{1}$ \\ ${ }^{1}$ Kuban State Agrarian University. I.T. Trubilina, Kalinina str., 13, Krasnodar, 350044, Russia
}

\begin{abstract}
Methods of disposal of manure / litter. There is a large amount of biological waste as a source of organic nitrogen in humus-forming fertilizer. The solution to this situation is the use of a new technological process - blending manure / litter with slaughter waste, as well as subsequent autoclave treatment and drying of the mixture. Equipment for manure / litter drying can be installed on the territory of the livestock / poultry complex in a convenient location. Installation options will be different, depending on the type of manure / litter, the presence / absence of slaughter production, the type of animals or birds, but only slightly. The set of equipment will be almost the same in all cases. As a fundamental decision on the use of new technology at the state level would be the following. Logistical, technological and territorial unification of two major tasks: disposal of solid waste with obtaining huge amounts of thermal energy and simultaneous disposal of manure / litter to produce humusforming fertilizer. The economic efficiency of the proposed technology is determined by the cost of drying. The production of dried fertilizer is very energy intensive, since have to evaporate huge amounts of water.
\end{abstract}

\section{Introduction}

The development of animal husbandry and poultry farming in the Russian Federation has created serious problems of waste disposal [1]. The problems are equally technically complex, but the volumes of manure / droppings are so huge and spectacular that almost only this issue is discussed.

The existing customary technologies for the disposal of manure / droppings export to the fields [Bazarov], fermentation, vermiculation, thermal drying, etc.

do not solve problems for a number of technical, technological, logistical reasons, but, most importantly, they do not give a significant economic effect after disposal manure / droppings in any way [2-5].

Consideration of the reasons for this is an interesting task, but it is not our goal, so it will not be considered. We just accept it as a fact, otherwise this problem would not exist.

The main reason for not solving of the problem of manure / litter disposal is an attempt to solve it as a separate technical problem of a local nature. The local problem was solved by previously known or new, at that time, methods from industries that were close in terms

\footnotetext{
${ }^{*}$ Corresponding author: natamamas@mail.ru
} 
of technological content and goals, that is, by methods and techniques characteristic of these industries.

The added value in these industries, is usually significant, due to the intellectual component, therefore, the cost of external resources in them is secondary. In our case - to process manure / dung into something useful - the main energy resources and other nonintellectual costs, so the borrowed technologies are very expensive to solve this problem. The costs of solving a problem of this magnitude in the form of consumption of electricity, gas, water, the use of land resources for the location of production, logistics costs, etc., are also becoming enormous.

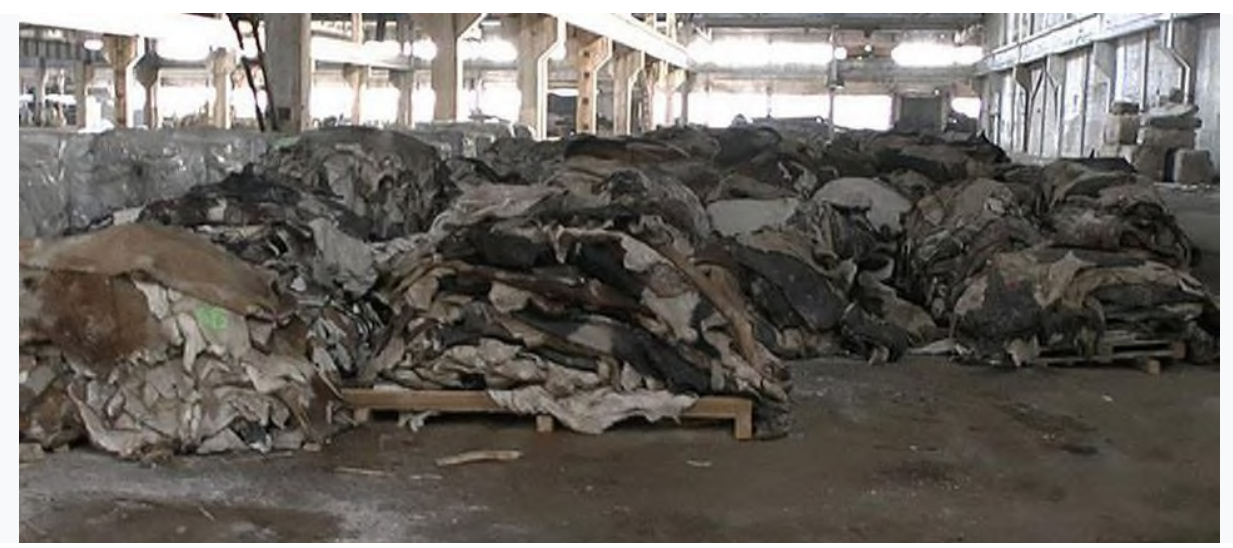

Fig. 1. Animal skins.

If a domestic producer disposes of $100 \%$ of the manure / droppings throughout the country, where will the resources and workers come from? You will need hundreds of thousands of hands, and cost of resources is high enough for any given manufacturer. There is a typical vicious situation of "work for the sake of work" has developed, encouraged and initiated by law.

The solution to this problem on a national scale and for an individual manufacturer exists and is a comprehensive solution [7-9] in conjunction with the utilization of municipal solid waste as a source of thermal technological energy (MSW also has a significant scale, there will be enough for everyone).

\section{Main part}

The solution to the problem of recycling today [10] is revolutionary and is perceived, as the experience of communication with production managers shows, with difficulty or even negatively. After all, you have to change a lot and the usual thing, including your own thinking. To understand the feasibility of a new technological concept, we will consider the issue in stages.

The primary answer is: what should be the product obtained from manure / dung so that it can be an economically profitable commodity - fertilizer?

Everyone knows that a humus-forming fertilizer from manure / dung [11-13] must meet the following requirements:

- guaranteed sterility against parasites, microorganisms;

- low germination of weed seeds;

- the presence of moisture in the amount of $8-10 \%$ allows you to overcome the compaction, ensure flowability, friability and the ability to transport over long distances

- contained nitrogen in organic form. 
There are the most common technologies for industrial processing of manure/manure fermentation and thermal drying, but they do not meet two main requirements at the same time.

Fermentation does not remove excess moisture and does not guarantee sterility, thermal drying does not guarantee sterility and low germination and leads to loss of nitrogen when heated. Manufacturers of dried manure / manure add mineral nitrogen-containing fertilizers, actually selling organomineral mixtures. This option is not suitable for everyone, since mineral fertilizers are characterized by a disadvantage when they depend on the weather, there is a risk of overdose when applied, and strict storage conditions. Therefore, this product and this method of using organic products are not in high demand.

A huge disadvantage of drying manure/manure is that it consumes $25-40 \%$ of the process heat when drying with a waste stream of moist air or gases (depending on the drying mode and time of year). When processing millions of tons of manure/manure, this can be a decisive argument when using this technology.

We do not consider other and more exotic methods of manure/manure disposal, as they, in our opinion, are generally far from real production. Therefore, the situation as a whole can be called a "dead end".

Second question: What should I do?

The solution to this situation is the use of a new technological process-blending manure/manure with slaughter waste, as well as subsequent autoclave treatment and drying of the mixture. The optimal drying method is contact drying through the heating wall, which provides the highest efficiency actions.

Processing of biological waste (cases, veterinary seizures and entrails, blood, bones, feathers, hooves, etc.) is energy-intensive due to the high moisture content, the fat contained dramatically extends the time for its evaporation, the waste taken separately from any production is not technological and requires blending with waste from other industries [3]. For example, the feather and biological waste from the slaughter of pigs, the internal organs and feathers of chickens, as well as the bones of cattle. In General, profitable production of meat and bone meal is technically and technologically more complex than the main production (meat or poultry) and riskier if all the requirements of sanitation, veterinary medicine and ecology are met.

The use of self - produced meat and bone meal in feeding diets has sharply narrowed. As a result, there is a large amount of biological waste as a source of organic nitrogen in the humus-forming fertilizer. At the same time, the task of recycling animal and poultry waste that is unsuitable for the production of meat and bone meal is being solved. Or even the entire volume of this waste.

The third argument: Practical use of new technology, equipment features.

A new technology for obtaining dried fertilizer - the so-called autoclave technology that meets all the basic requirements-was developed and used in the industrial production of Crimea. According to this technology, the product is obtained during processing in KVM 4,6 waste heat boilers used in the production of meat and bone meal. Removal of moisture from manure/manure is carried out under vacuum, which provides economic efficiency of drying and prevents the release of bad-smelling substances into the air, and sterilization occurs at $150^{\circ} \mathrm{C}$ (for comparison, it is known that medical instruments are sterilized at $132^{\circ} \mathrm{C}$ ). Organic nitrogen is formed by adding biological waste to the mass of manure/manure processed in the KVM - 4,6 boiler in a certain way. The resulting fertilizer contains nitrogen in a bound form and is consumed during the entire period of plant growth.

The core of this technology is the use of the well-known autoclave boiler KVM-4,6 as a reliable, trouble-free and safe equipment in operation. Direct contact of the heating walls with the droppings causes a complete absence of technological heat losses, since there is no intermediate heat carrier in drum dryers. The released steam is completely captured during 
condensation. The vacuum is created by the operation of the well-known water ring pump VVN-3. The condensed steam contains almost all the bad-smelling substances and ammonia, and is processed by passing through a layer of $2 \%$ aqueous $\mathrm{NaOH}$ solution, so harmful and bad-smelling emissions of substances are practically not formed.

The source of heat energy is a solid fuel boiler of the original design (produced in Belarus). The heat carrier is high-temperature AMT-300T oil. The choice in its favor was made due to the lack of pressure in the oil system, in the operating temperature range. Such a boiler is not controlled by Rostekhnadzor in accordance with Federal standards and regulations in the field of industrial safety "Rules for industrial safety of hazardous production facilities where equipment operating under excessive pressure is used".

Circulation is carried out by pumping gear pump (manufacturer "Livnygidromash") oil through the grate from the pipes to the boiler KVM-4,6, the speed of heating the oil is very high, because this grate has a huge heating surface.

A low injection-type flue helps to increase the cooling rate of gases. Gorenje mode is regulated by changing the speed of the fan motor by the frequency Converter in manual mode or completely turning off the fan automatically within the limits of the set coolant temperatures. At the end of the working day, the boiler is automatically switched off after burning the remaining fuel when the required temperature $\left(60 \div 80^{\circ} \mathrm{C}\right)$ is reached from the heat carrier.

To automate the operation of the boiler, an automatic solid fuel loading unit has been developed in the form of coal, wood briquettes and wood chips of any size and shape, which provides a level of automation of combustion processes that is not inferior to gas boilers. Gorenje A Stoker is not required to load fuel. It will be necessary to remove ash from the ash pan only once a day (during the shutdown period after 23 hours of continuous operation) (which will be $\sim 1 \%$ of the mass of fuel consumed).

In General, the boiler is extremely reliable and suitable. All the main units-pump, fan, chimney, heat exchanger-are easily removed, and only the brick walls reinforced with sheet steel remain. The main unit is a tube heat exchanger, which is removed in 2 hours. No other design of similar equipment has such distinctive properties. In them, any attempt to get inside and replace something is simply impossible (or it entails major repairs).

The actual oil temperature used is up to $170^{\circ} \mathrm{C}$ (pump temperature resistance is $200^{\circ} \mathrm{C}$ ). The drying speed is very high, because inside the boiler KVM-4,6 agitators constantly move the drying mass, while homogenization and abrasion of plant and animal inclusions occur. Any specified percentage of moisture is easily achieved.

At this temperature of the heat carrier and constant mixing, sterility is guaranteed in relation to the intestinal microflora and weed seeds. The nitrogen content will be determined by the freshness of the litter and the amount of biological waste introduced.

All further operations with dried manure or droppings are performed using conventional methods.

By combining in one technology the solution of two separate tasks, one of which involves the disposal of manure/manure, and the second includes the disposal of biological waste, i.e. the production of meat and bone meal, it was possible to get new and unexpected technological advantages that solve both problems completely, and this allowed us to get a profitable large-capacity business. Northern Europe, North Africa, the middle East, Central Asia, Central and Northern regions of Russia-these are the regions where the soil contains most of the sand and requires millions of tons of manure/manure to raise soil fertility.

The economic efficiency of the proposed technology is determined by the cost of drying. The production of dried fertilizer is very energy-intensive, since it is necessary to evaporate huge volumes of water. This is a physical reality and it is impossible to circumvent it with any technical tricks. The organization of large-scale fertilizer production will require a huge amount of thermal energy. 
It should be noted that the question arises: Where to find a large amount of affordable and cheap thermal energy.

To create a profitable production, it is proposed to use fuel from prepared MSW waste obtained using the original technology (Belgorod). This technology uses the internal energy and material resources of MSW to save or completely eliminate external heat consumption for heating and technological needs, which dramatically reduces the cost of the fuel produced. According to calculations, the available internal energy in MSW at landfills is only enough for drying the entire mass of MSW and there are surpluses of more than $200 \%$ for the implementation of technological processes.

When water vapor condenses, a valuable resource is obtained in the form of tens of thousands of tons of technical distillate (ready water for boilers, etc.), which can be used in agricultural production.

The presence of such a huge amount of heat energy is the basis for the implementation of a new technology for drying manure/manure, using a contact method of heat transfer from the heated wall directly to the mass of manure. A set of machines and units that implement this technology for any manure/manure is characterized by exceptional simplicity and reliability, and most importantly, it uses any solid fuel (wood and wood waste, coal, peat, MSW) or biogas, including those generated in a landfill.

How to use the new technology of manure/manure disposal at an existing livestock or poultry enterprise?

First of all, it is necessary to solve the issue of fuel supply. To do this, contact Ecotrans or any similar organization and sign a contract for the supply of wood fuel or RDF fuel. Eco trans owns the fuel production technology and can start production if there is a permanent customer. An alternative way is to buy, partially manufacture and install your RDF fuel preparation equipment at any suitable landfill. Fuel will be cheaper.

Equipment for drying manure / litter can be installed on the territory of the livestock / poultry complex in a convenient place. Installation options will be different, depending on the type of manure / dung, the presence / absence of slaughter production, the type of animals or birds, but only slightly. The set of equipment will be almost the same in all cases.

The following would be the principal decision on the use of new technology at the state level. Logistic, technological and territorial integration of two major tasks: utilization of solid waste with the receipt of huge amounts of thermal energy and the simultaneous utilization of manure / dung to obtain humus-forming fertilizer. Since it is impossible to accumulate thermal energy, it is necessary to locate two industries on the same territory, interconnected by a technological stage for the transfer of thermal energy.

In fact, this is a territorial cluster for waste disposal for nearby livestock / poultry enterprises and settlements. The equipment that implements these technologies is rather small-sized, transportable and, in general, commercially available. It is possible to organize such recycling centers anywhere, for example, on existing small landfills serving the adjacent territories. This will sharply reduce the cost of transporting solid waste and animal / poultry waste.

Manufacturing of original components and assemblies at the nearest machine-building enterprises and assembly on site. Structurally, they are simple and complex equipment for manufacturing is not required.

The main equipment - an oil-tube boiler, a KVM-4.6 boiler, etc. - is purchased, it can only be installed and "strapped". Boiler KVM-4.6 generally buy used, there is no difference in operation, and the price is several times less.

The proposed technology was previously used by a private enterprise "Semya" in Simferopol in the period $2000-2010$. The only difference is that a gas boiler house with boilers E-1 / 0.9 was used [14-18]. The heat carrier was "crumpled" steam after the 
production of meat and bone meal and fodder fat, so the question of prime cost was not acute.

As an example, we give a block diagram of the complete utilization of pig manure and the calculation of the cost of drying pig manure.

The cost of drying pig manure is maximum due to the huge amount of moisture, for other types of manure / dung it will be several times less in proportion to the decrease in moisture content.

Calculation of the cost of drying pork manure: Waste volume 460 tons per shift with a moisture content of $97 \%$, Dry matter: $460 \mathrm{t} \times 0.03=12 \mathrm{t}$, Water: $460 \mathrm{t}-12 \mathrm{t}=448 \mathrm{t}$ To reduce the cost of equipment and ensure rhythm, we take the operating time of 23 hours a day. The technological process is shown in the block diagram (attached). The required heat to heat the droppings to $70^{\circ} \mathrm{C}$ (in fact, protein denaturation occurs already at $60^{\circ} \mathrm{C}$, but in the calculation we take a deliberately high temperature): $\mathrm{Q}=\mathrm{c} \times \Delta \mathrm{t} \times \mathrm{M}=1 \times 60 \times 448000=$ $26880000 \mathrm{kcal}$ where $\mathrm{c}=1 \mathrm{kcal} / \mathrm{kg}$ is the heat capacity of water $\Delta \mathrm{t}=700-100=600-$ the difference between the final and initial temperatures of the litter $M=448000 \mathrm{~kg}$ - mass of heated water The required amount of heat for drying manure in one hour: $q=Q / 23=$ $26880000 / 23=1168700 \mathrm{kcal}$ In $\mathrm{kW} \mathrm{q}=1168700 \times 1.16 \times 10-3=1355.7 \mathrm{~kW}$

As fuel, we take: RDF fuel (calorific value $5.22 \mathrm{kWh} / \mathrm{kg}$ ), heating oil (calorific value $11.96 \mathrm{kWh} / \mathrm{kg}$ ), TMSSh coal (calorific value $6.7 \mathrm{kWh} / \mathrm{kg}$, produced by the Kamyshansky mine), wood chips (the calorific value is $4.2 \mathrm{kWh} / \mathrm{kg}$ ).

Fuel amount in the first hour of operation: Wood fuel: $\mathrm{m} 0=1355.7 / 4.2=322.78 \mathrm{~kg}$

Coal: $\mathrm{m} 0=1355.7 / 6.7=202.34 \mathrm{~kg}$, Heating oil: $\mathrm{m} 0=1355.7 / 11.96=113.38 \mathrm{~kg}$, RDF fuel: $\mathrm{m} 0=1355.7 / 5.22=259,71 \mathrm{~kg}$.

To save fuel, we use preheating of manure with the warmth of hot water after phase separation in the OGSh settling centrifuge.

Taking heat losses into account, the return heat from the initial heating is approximately $70 \%$. Then the consumption of heat energy for heating the manure in each subsequent hour of operation: $1355.7 \times 0.3=406.71 \mathrm{~kW}$, Amount of fuel: Wood fuel: $\mathrm{m} 1=406.71 / 4.2=$ $96.83 \mathrm{~kg}$, Coal: $\mathrm{ml}=406.71 / 6.7=60.7 \mathrm{~kg}$, Heating oil: $\mathrm{ml}=406.71 / 11.96=34.0 \mathrm{~kg}$, RDF fuel: $\mathrm{ml}=406.71 / 5.22=77.91 \mathrm{~kg}$

The moisture content of the manure after dehydration in the OGSh centrifuge is approximately $20 \%$, then the mass of raw materials entering the final drying into the KVM4.6 boiler is 15 tons. It is necessary to evaporate more $\mathrm{mw}=3000 \mathrm{~kg}$ of water (absolutely dry manure) $\mathrm{q} 2=\mathrm{mv}\left(\mathrm{i}^{\prime \prime}-\mathrm{i}\right) \mathrm{q} 2=3000 \times(639.1-69.98)=1707000 \mathrm{kcal}$ where $\mathrm{i}^{\prime \prime}$ is the enthalpy of dry saturated steam at atmospheric pressure $\left(i^{\prime \prime}=639.1 \mathrm{kcal} / \mathrm{kg}\right) \mathrm{i}^{\prime}$ - enthalpy of water $\left(i^{`}=69.98 \mathrm{kcal} / \mathrm{kg}\right)$ in $\mathrm{kW} \mathrm{q2}=1707000 \times 1.16 \times 103=1980.12 \mathrm{~kW}$

Fuel quantities to evaporate residual moisture:

Wood fuel: $\mathrm{m} 2=1980.12 / 4.2=471.5 \mathrm{~kg}$, Coal: $\mathrm{m} 2=(1980.12) / 6.7=295.2 \mathrm{~kg}$, Heating oil: $\mathrm{m} 2=(1980.12) / 11,96=165.5 \mathrm{~kg}, \mathrm{RDF}$ fuel: $\mathrm{m} 2=(1980.12) / 5.22=379.3$ $\mathrm{kg}$

Daily fuel consumption: Wood fuel: $322.68 \mathrm{~kg}+(96.83 \mathrm{~kg} \times 22$ hours $)+471.5 \mathrm{~kg}=$ $2924.54 \mathrm{~kg}$, Coal: $202.34+(60.7 \mathrm{~kg} \times 22$ hours $)+295.2 \mathrm{~kg}=1832.94 \mathrm{~kg}$

Heating oil: $113.38 \mathrm{~kg}+(34 \mathrm{~kg} \times 22$ hours $)+165.5 \mathrm{~kg}=1026.88 \mathrm{~kg}$

RDF fuel: $259.71 \mathrm{~kg}+(77.91 \mathrm{~kg} \times 22$ hours $)+379.3 \mathrm{~kg}=2353.03 \mathrm{~kg}$

Annual fuel consumption:

Fuelwood: $2924.54 \mathrm{~kg} \times 365$ days $=1067457.1 \mathrm{~kg}$

Coal: $1,832.94 \mathrm{~kg} \times 365$ days $=669023.1 \mathrm{~kg}$

Heating oil: $1026.88 \mathrm{~kg} \times 365$ days $=374811.2 \mathrm{~kg}$

RDF fuel: $2353.03 \mathrm{~kg} \times 365$ days $=858855.95 \mathrm{~kg}$

Fuel price:

Wood fuel (wood chips): $150 \div 200$ rubles / ton. We accept 200 rubles / ton 
Coal: 1650 rubles / ton

Heating oil: 19,000 rubles / ton

RDF fuel: $1000 \div 1500$ rubles / ton. We accept 1250 rubles / ton

Fuel cost for drying daily volume of manure / litter:

Wood fuel: $2924.54 \times 0.2=584.9$ rubles

Coal: $1832.94 \times 1.65=3024.3$ rubles

Heating oil: $1026.88 \times 19=19510.72$ rubles

RDF fuel: $2353.03 \times 1.25=2941.28$ rubles

Annual fuel costs:

Wood fuel: 584.9 rubles $\times 365=213488.5$ rubles

Coal: 3024.3 rubles $\times 365=1103869.5$ rubles

Heating oil: 19510.72 rubles $\times 365=7121412.8$ rubles

RDF fuel: 2941.28 rubles $\times 365=1073561.2$ rubles

\section{Conclusions}

Based on the cost of fuel, delivery terms, availability, delivery logistics, combustion technology (including ash removal), the possibility of automating fuel supply, etc., it is optimal to use fuel chips and RDF fuel (the supplier is the same). Use coal as a backup fuel.

Any costs for processing manure / dung are offset by income from the sale of fertilizer. For your information, the wholesale cost of dried poultry droppings is 5-10 rubles $/ \mathrm{kg}$, therefore, the daily yield from the production of 12 tons of fertilizer at an equal price of 60 120 thousand rubles. An additional effect is the absence of costs for the disposal of growing and slaughter waste as a separate technological chain with the necessary equipment, personnel, product quality, etc. The waste itself will simply "drown" in the ocean of manure / dung and will not affect the cost price in any way. moisture content, and the quality of the final product will dramatically increase.

Equipment used: buffer tank, OGSh centrifuge, oil tube boiler, KVM-4.6 boiler, granulator - very simple and reliable. Equipment reliability and maintainability are the most important criteria when choosing a technological process.

\section{References}

1. J. Mason, Studies in Environmental Science, Geomorphology 248, 363-381 (2015) doi.org/10.1016/j.geomorph.2015.08.004

2. D.J.H. Blake, Advances in Food Security and Sustainability 4, 33-65 (2019) doi.org/10.1016/bs.af2s.2019.06.003

3. U. Barua, International Journal of Disaster Risk Reduction 50, 101836 (2020) doi.org/10.1016/j.ijdrr.2020.101836

$\begin{array}{lllll}\text { 4. P. Xie, Journal of } & 125222\end{array}$ (2020) doi.org/10.1016/j.jhydrol.2020.125222

5. B. Minasny, Geoderma 264, 301-311 (2016), doi.org/10.1016/j.geoderma.2015.07.017

6. A. Nankabirwa, Ecological Indicators 107, $105563 \quad$ (2019) doi.org/10.1016/j.ecolind.2019.105563

7. N.S. Embabi, The Egyptian Journal of Remote Sensing and Space Science 17, 41-60 (2014) doi.org/10.1016/j.ejrs.2014.02.002

8. P. Smedley, Applied Geochemistry 84, 387-432 (2017) doi.org/10.1016/j.apgeochem.2017.05.008 
9. S. Kuehl, Earth-Science Reviews 153, 301-334 (2016), doi.org/10.1016/j.earscirev.2015.10.001

10. J. Gaillardet, Treatise on Geochemistry (Second Edition) 7, 195-235 (2014), doi.org/10.1016/B978-0-08-095975-7.00507-6

11. V.U. Smakhtin, Journal of Hydrology 240, 147-186 (2001) doi.org/10.1016/S00221694(00)00340-1

12. P. Xie, Journal of Hydrology $\mathbf{5 9 0}, 125222$ doi.org/10.1016/j.jhydrol.2020.125222

13. X. Cao, Agricultural Water Management 241, 106355 (2020) doi.org/10.1016/j.agwat.2020.106355

14. E. Shtull-Trauring, Water
(2020)

15. F. Wei, Journal of Cleaner Production 273, 10, 122537 (2020)doi.org/10.1016/j.jclepro.2020.122537

16. M. Natalia, Advances in Agricultural and Biological Sciences 4, 13-19 (2018) doi.10.22406/aabs-18-4.4-13-19

17. M. Natalia, Advances in Agricultural and Biological Sciences 4, 21-26 (2018) doi. 10.22406/aabs-18-4.4-21-26

18. M. Natalia, Advances in Agricultural and Biological Sciences 4, 5-12 (2018) doi: 10.22406/aabs-18-4.6-5-12 